\title{
Sea Level Rise Impact on Atoll Islands: Implication to SDG 6
}

\author{
Xin Yi Kh'ng', Su Yean Teh", ${ }^{1, *}$ Hock Lye Koh $^{2}$ \\ ${ }^{1}$ School of Mathematical Sciences, Universiti Sains Malaysia, 11800 USM, Pulau Pinang, Malaysia \\ ${ }^{2}$ Jeffrey Sachs Center on Sustainable Development, Sunway University, Jalan Universiti, Bandar Sunway, 47500 Selangor, Malaysia
}

Copyright $\odot 2019$ by authors, all rights reserved. Authors agree that this article remains permanently open access under the terms of the Creative Commons Attribution License 4.0 International License

\begin{abstract}
Low-lying atoll islands that depend heavily on fresh groundwater for survival are particularly vulnerable to sea level rise (SLR), which calls for appropriate climate action SDG 13. As the sea level rises, the associated increase in surface seawater inundation and subsurface saltwater intrusion will reduce the availability of fresh groundwater due to permanent salinization of groundwater with corresponding thinning of freshwater lens. This paper provides scientific insights on how freshwater lens in atoll islands respond to SLR. Simulations on saturated-unsaturated variable-density groundwater flow with salt transport are performed by the groundwater flow and solute transport model SUTRA (Saturated-Unsaturated Transport) developed by the U.S. Geological Survey. Model simulations and statistical analyses suggest that freshwater lens thickness depends mainly on groundwater recharge rate, island size and aquifer hydraulic conductivity. The impact of various geo-hydrologic parameters on fresh groundwater sustainability is then analyzed to explore feasibility of increasing groundwater recharge through rainwater harvesting, as a mitigation measure. The implication to the achievement of sustainable clean water and sanitation for all (SDG 6) is also discussed.
\end{abstract}

Keywords Climate Action SDG 13, Freshwater Lens, SDG 6, SUTRA

\section{Introduction}

Fast population growth coupled with rapid economic development is imposing vastly increasing demands on precious water resources. According to the United Nations World Water Development Report 2018, an estimated 3.6 billion people, nearly half the global population, currently live in areas that are potentially water-scarce for at least one month per year [1]. Recognizing the importance of sustainable water security, the United Nation endorses the
Sustainable Development Goal 6 (SDG 6) of 'Ensuring availability and sustainable management of clean water and sanitation for all'. Global climate change and the anticipated rise in local sea levels could further exacerbate pressure on already-stressed freshwater resources. An immediate effect of sea level rise (SLR) will be on the coastal freshwater lenses that sit on top of saline groundwater. Surface seawater inundation and subsurface saltwater intrusion associated with SLR will cause a serious problem in the form of permanent salinization of fresh groundwater, making the water unsuitable for human consumption and agricultural use. The degradation of water quality and diminishing quantity will have profound impact on coastal communities, particularly in low-lying atoll islands throughout the Pacific and Indian Oceans, as they depend critically on the fresh groundwater stored in the freshwater lenses [2]. Consequently, alternative water resources (AWRs) such as rainwater harvesting, water reuse and desalination have received increasing acceptance as supplements to these scarce traditional water supplies. The current decline in fresh groundwater availability necessitates the formulation of sustainable groundwater management through proper assessment and utilization of the available resources.

Previous modelling studies have investigated the adverse impacts of SLR on the freshwater lenses of islands or coastal aquifers [3,4]. Notably, Ataie-Ashtiani et al. [5] discover that surface seawater inundation controls the degree of subsurface saltwater intrusion, and that the impact of SLR on subsurface saltwater intrusion may be mitigated by increased groundwater recharge [6,7]. Rainwater harvesting (RWH) has emerged as a viable alternative source of groundwater recharge by utilizing rainwater and its runoff $[8,9]$. However, the role of RWH in alleviating the loss of groundwater aquifer due to SLR is not yet adequately quantified. Hence, no official quantitative guidance on RWH as an artificial recharge technique is currently available. In order to sustainably restore groundwater aquifers by $\mathrm{RWH}$, it is important to examine quantitatively how the fresh groundwater 
availability is related to several controlling geo-hydrologic parameters. This quantitative analysis is critical in evaluating the potential role of RWH and in facilitating the conjunctive management of rainwater and groundwater resources for adaptation to future climate change. This study develops a quantitative framework for assessing RWH capacity to mitigate the effect of SLR on coastal aquifer, with a particular focus on atoll islands. For this purpose, the United States Geological Survey's (USGS) three-dimensional variable-density saturated-unsaturated groundwater flow and solute transport model, SUTRA is used to quantitatively assess the potential consequences of SLR on the availability and quality of subsurface water resources. This can be achieved through the observation of lens morphology, thickness and volume in response to the imposed SLR scenarios. Subsequently, the conjunctive use of groundwater and rainwater in an integrated framework is explored for development of more feasible, effective and sustainable water management strategies against future SLR, consistent with the aspirations of SDG 6.

The following section presents the mass balance equations for saturated-unsaturated variable density groundwater flow and solute transport model. Subsequently, the derivation of an analytical formula denotes the thickness and volume of extractable water in the freshwater lens is presented. Sensitivity analysis is performed by using this analytical formula to identify the main geo-hydrologic parameters affecting freshwater lens thickness in island aquifers. Further, numerical simulations are carried out to further explore the relation between the parameters and freshwater lens thickness. Model validation is performed by comparing the simulation results with the analytical solutions for lens thickness. Then, the validated groundwater simulation model is used to assess the extent of salinization and availability of freshwater resources as a result of SLR. The last section provides an estimate of RWH capacity needed to mitigate the loss of groundwater aquifer due to SLR, with the recommended storage tank size.

\section{Groundwater Model}

The USGS SUTRA (Saturated-Unsaturated Transport) model is used to simulate saturated-unsaturated density-dependent groundwater flow with solute or energy transport [10]. Equations (1) and (2) show the coupled fluid and solute mass balance equations in SUTRA.

$$
\begin{gathered}
\left(S_{w} \rho S_{O p}+\varepsilon \rho \frac{\partial S_{w}}{\partial p}\right) \frac{\partial p}{\partial t}+\varepsilon S_{w} \frac{\partial \rho}{\partial C} \frac{\partial C}{\partial t}- \\
\nabla\left[\left(\frac{k k_{r} \rho}{\mu}\right) \cdot(\nabla p-\rho g)\right]=Q_{p} \\
\frac{\partial\left(\varepsilon S_{w} \rho C\right)}{\partial t}+\nabla \cdot\left(\varepsilon S_{w} \rho v C\right)- \\
\nabla \cdot\left[\varepsilon S_{w} \rho\left(D_{m} I+D\right) \cdot \nabla C\right]=Q_{p} C^{*}
\end{gathered}
$$

Here, $S_{w}(-)$ is the water saturation, $\rho\left(\mathrm{kg} \mathrm{m}^{-3}\right)$ is the fluid density, $S_{o p}\left(\mathrm{~m} \mathrm{~s}^{2} \mathrm{~kg}^{-1}\right)$ is the specific pressure storativity, $\varepsilon$ $(-)$ is the porosity, $p\left(\mathrm{~kg} \mathrm{~m}^{-1} \mathrm{~s}^{-2}\right)$ is the fluid pressure, $t(\mathrm{~s})$ is the time, $C\left(\mathrm{~kg} \mathrm{~kg}^{-1}\right)$ is the mass-based solute concentration, $k\left(\mathrm{~m}^{2}\right)$ is the permeability tensor, $k_{r}(-)$ is the relative permeability, $\mu\left(\mathrm{kg} \mathrm{m}^{-1} \mathrm{~s}^{-1}\right)$ is the fluid viscosity, $g\left(\mathrm{~m} \mathrm{~s}^{-2}\right)$ is the gravitational acceleration, $Q_{p}\left(\mathrm{~kg} \mathrm{~m}^{-3} \mathrm{~s}^{-1}\right)$ is the fluid mass source, $v\left(\mathrm{~m} \mathrm{~s}^{-1}\right)$ is the fluid velocity, $D_{m}\left(\mathrm{~m}^{2} \mathrm{~s}^{-1}\right)$ is the molecular diffusion, $I(-)$ is the identity tensor, $D\left(\mathrm{~m}^{2} \mathrm{~s}^{-1}\right)$ is the dispersion tensor and $C^{*}\left(\mathrm{~kg} \mathrm{~kg}^{-1}\right)$ is the solute concentration of the fluid sources. The standard Galerkin finite element method is used to discretize in space with quadrilateral elements and a weighted difference method is used for temporal discretization. Construction and preparation of model input is done in Argus Open Numerical Environments (Argus ONE) using the SUTRA Plug-In Extension (PIE). The simulation results are then visualized using Model Viewer, a USGS post-processing graphic utility [11].

As part of model validation, we use an analytical formula to assess the thickness and volume of freshwater lens in coastal aquifers [12]. Consider a circular island of radius $R(\mathrm{~m})$ receiving an effective recharge from rainfall at a rate $W\left(\mathrm{~m} \mathrm{~s}^{-1}\right)$ and with a freshwater lens sitting on top of saline groundwater, as illustrated in Figure 1. Darcy's law is applied to groundwater discharge $Q\left(\mathrm{~m}^{3} \mathrm{~s}^{-1}\right)$ in the radial $r(\mathrm{~m})$ direction [13], yielding:

$$
Q=-2 \pi r K(z+h) \frac{d h}{d r}=\pi r^{2} W
$$

where $K\left(\mathrm{~m} \mathrm{~s}^{-1}\right)$ is the hydraulic conductivity, $h(\mathrm{~m})$ is the water table elevation above sea level and $z(m)$ is the depth of the freshwater-seawater interface below sea level. The relationship between $h$ and $z$ is expressed by the Ghyben-Herzberg equation (4), which assumes a sharp interface between fresh and saline groundwater [14]:

$$
z=\frac{\rho_{f}}{\rho_{S}-\rho_{f}} h=\frac{\rho_{f}}{\Delta \rho} h
$$




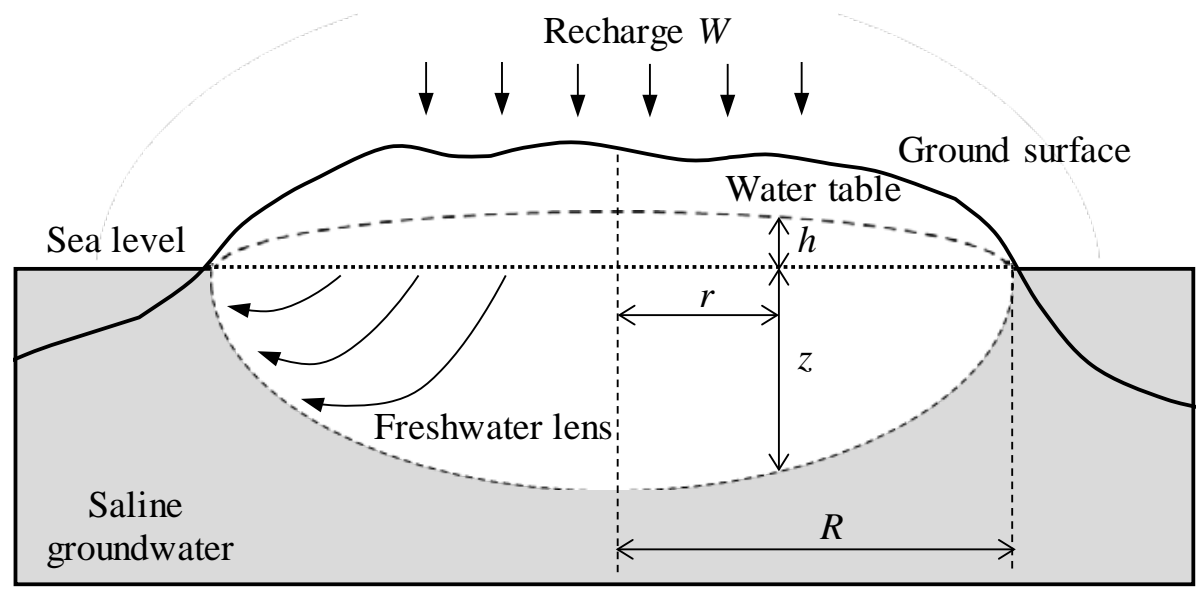

Figure 1. Freshwater lens in a circular island

The freshwater and seawater densities are denoted by $\rho_{f}$ and $\rho_{s}\left(\mathrm{~kg} \mathrm{~m}^{-3}\right)$, respectively. Combining Equation (3) and Equation (4) gives Equation (5):

$$
-2 \pi r K\left(z+\frac{\Delta \rho}{\rho_{f}} z\right) \frac{\Delta \rho}{\rho_{f}} \frac{d z}{d r}=\pi r^{2} W
$$

while the rearrangement of Equation (5) yields Equation (6):

$$
z d z=-\frac{W r}{2 K\left(1+\Delta \rho / \rho_{f}\right) \Delta \rho / \rho_{f}} d r
$$

The solution of Equation (6) is given as Equation (7):

$$
z^{2}=-\frac{W r^{2}}{2 K\left(1+\Delta \rho / \rho_{f}\right) \Delta \rho / \rho_{f}}+C
$$

The integration constant $C$ can be determined using the boundary condition of $z=0$ when $r=R$. With this, Equation (7) can then be expressed as Equation (8):

$$
z=\sqrt{\frac{W\left(R^{2}-r^{2}\right)}{2 K\left(1+\Delta \rho / \rho_{f}\right) \Delta \rho / \rho_{f}}}
$$

Thus, the depth $z$ to seawater at any location $r$ is a function of the recharge rate $W$, island radius $R$ and aquifer hydraulic conductivity $K$. The maximum thickness of freshwater lens $z_{\max }$ is obtained by substituting $r=0$. Then the volume of extractable water in the freshwater lens $V\left(\mathrm{~m}^{3}\right)$, which has the shape of a semi-ellipsoid, is given by Equation (9) [15]:

$$
V=\frac{2}{3} \pi\left(1+\Delta \rho / \rho_{f}\right) z_{\max } R^{2} \varepsilon
$$

\section{Sensitivity Analysis}

The analytical solution presented in Equation (8) indicates that the thickness of the freshwater lens, which determines the available volume of fresh groundwater, is controlled by recharge rate $W$, island radius $R$ and aquifer hydraulic conductivity $K$. Here, sensitivity analysis is performed to identify the relative importance of each parameter $W, R$ and $K$ on lens thickness $z$. The normalized sensitivity index of $z$ with respect to a parameter is the ratio of the relative change in $z$ to the relative change in the parameter [16]. The sensitivity index of $z$ that depends differentiably on a parameter $p$ is defined in Equation (10):

$$
S_{p}^{z}=\frac{\partial z}{\partial p} \times \frac{p}{Z}
$$

Fig. 2(a) shows the sensitivity indices of $z$ relative to the parameters $W, R$ and $K$. The sensitivity indices show how significant each parameter contributes to $z$. A positive index means that any increase in parameter value corresponds to an increase in the $z$ value. The sensitivity analysis shows that $z$ is the most sensitive to the island radius $R$, with $S_{R}=+1.0$. This indicates that an increase (decrease) of $10 \%$ in $R$ will increase (decrease) $z$ by $10 \%$. The sensitivity indices for the recharge rate $W$ and aquifer hydraulic conductivity $K$ are +0.5 and -0.5 respectively.

Subsequently, numerical simulations are carried out to further explore the relation between freshwater lens thickness and the parameters $W, R$ and $K$. Fig. 3(a) shows that lens thickness increases with increasing recharge rate. Any decrease in groundwater recharge may allow further intrusion of saline water into the aquifer, causing a corresponding thinning of the freshwater lens. As illustrated in Fig. 3(b), the size of an island, particularly the width, appears to be linearly related to the lens thickness. Small islands $(R<400 \mathrm{~m})$ generally have thin lenses $(z<5$ $\mathrm{m})$ whereas large islands $(R>400 \mathrm{~m})$ generally have thick lenses ( $5 \mathrm{~m} \leq z \leq 25 \mathrm{~m}$ ). Small islands will receive limited volumes of recharge and consequently have small freshwater lens. Fig. 3(c) shows a logarithmic decrease in lens thickness with increasing aquifer hydraulic conductivity. The higher the hydraulic conductivity, the greater will be the rate of groundwater flow through an aquifer, thereby resulting in an increased inland extent of 
the seawater edge. To compare the numerical result with the analytical solution, the simulated freshwater-seawater interface is defined by $50 \%$ of seawater concentration [17]. Fig. 2(b) shows that analytical solutions for lens thickness are in a good agreement with the numerical results for all cases $\left(R^{2}=0.9959\right)$, indicating that the analytical solutions provide valid and comparable results even with the imposed simplifications and assumptions.
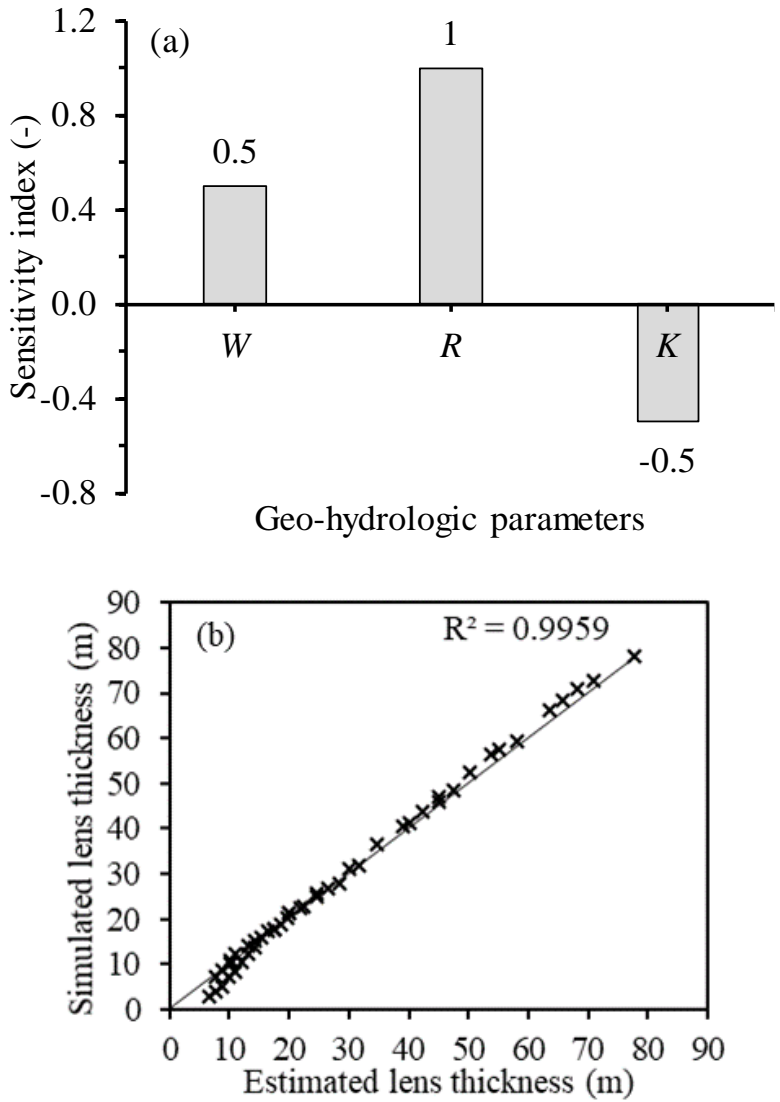

Figure 2. (a) Sensitivity indices of freshwater lens thickness relative to the geo-hydrologic parameters (b) Comparison between analytical and numerical solutions for freshwater lens thickness

\section{SLR Impact on Freshwater Availability}

The rate of global SLR is accelerated to $3.2 \pm 0.4 \mathrm{~mm}$ $\mathrm{yr}^{-1}$ during 1993-2003, from the average rate of $1.8 \mathrm{~mm}$ $\mathrm{yr}^{-1}$ during 1961-2003. Under the plausible worst case RCP 8.5 scenario, the Intergovernmental Panel on Climate Change (IPCC) has predicted a SLR of 0.5 to $1.0 \mathrm{~m}$ by the end of the $21^{\text {st }}$ century [18]. SLR of such magnitude could drastically reduce the width of atoll islands across the Pacific and Indian Oceans, thereby reducing the available volume of extractable groundwater from freshwater lens. Hence, in this section, we use SUTRA to assess the extent of salinization and availability of freshwater resources as a result of SLR.
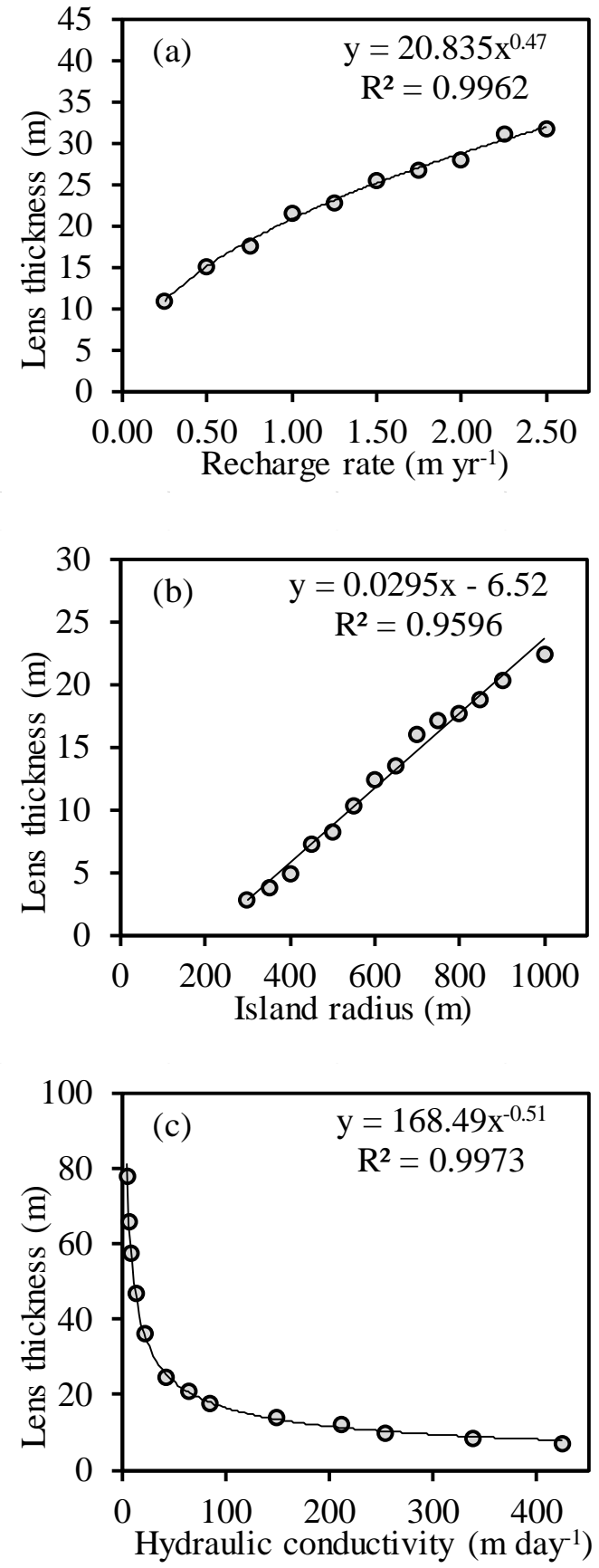

Figure 3. Sensitivity analysis results for each of the three parameters examined: (a) recharge rate $W$, (b) island radius $R$ and (c) hydraulic conductivity $K$

The computational setup for the three-dimensional simulation is illustrated in Figure 4 in 2D cross-sectional view and Figure 5 in 3D view. A hypothetical circular island of radius $800 \mathrm{~m}$ is used as the baseline model. The model domain is extended to a distance of $200 \mathrm{~m}$ offshore. The model domain is discretized into 238,472 nodes and 224,825 quadrilateral elements, with 25 layers that extend from the land surface to a uniform depth of $100 \mathrm{~m}$ below mean sea level (MSL). The element size in the radial direction is $15 \mathrm{~m}$ whereas the element size in the vertical 
direction varies from 1 to $5 \mathrm{~m}$. Initially, the model domain is assumed to be saline. Specified pressure boundaries are assigned to all nodes below sea level as well as to the seaward vertical boundary. Inflowing fluid at these nodes has a concentration of seawater $\left(C=0.0357 \mathrm{~kg} \mathrm{~kg}^{-1}\right)$. An inflow of rainfall infiltration at $0.75 \mathrm{~m} \mathrm{yr}^{-1}$ is applied evenly over the land surface, with inflowing rainwater having zero salinity. This corresponds to an average annual rainfall of $1.875 \mathrm{~m}$ with $60 \%$ runoff loss. A no-flow boundary is specified along the bottom of the domain. Table 1 summarizes the input parameters used for SUTRA model simulations.

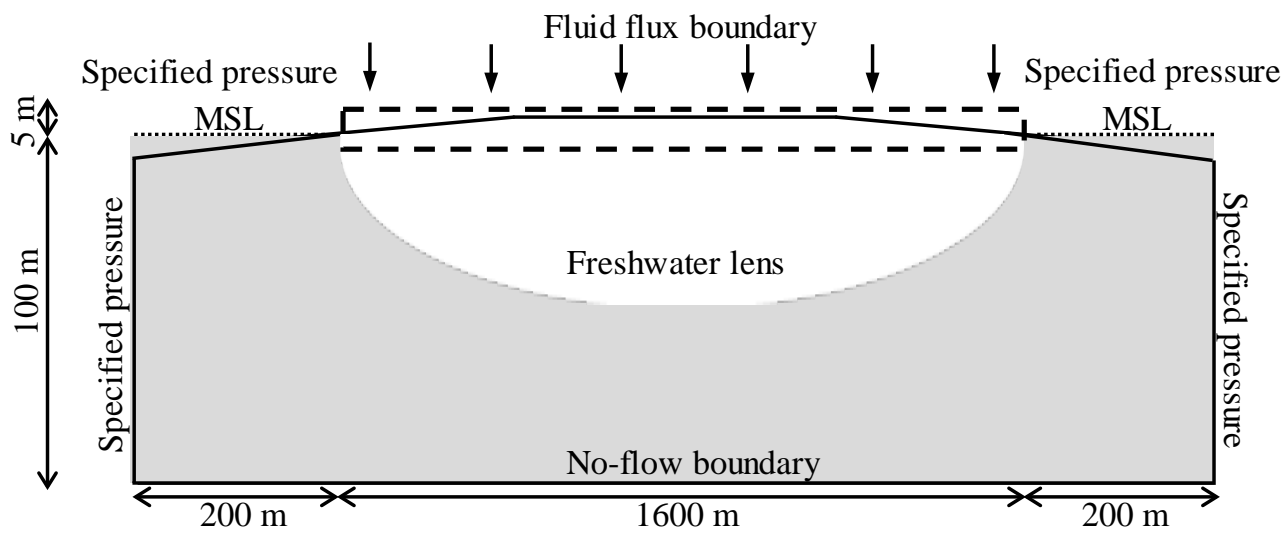

Figure 4. Model domain and assigned boundary conditions
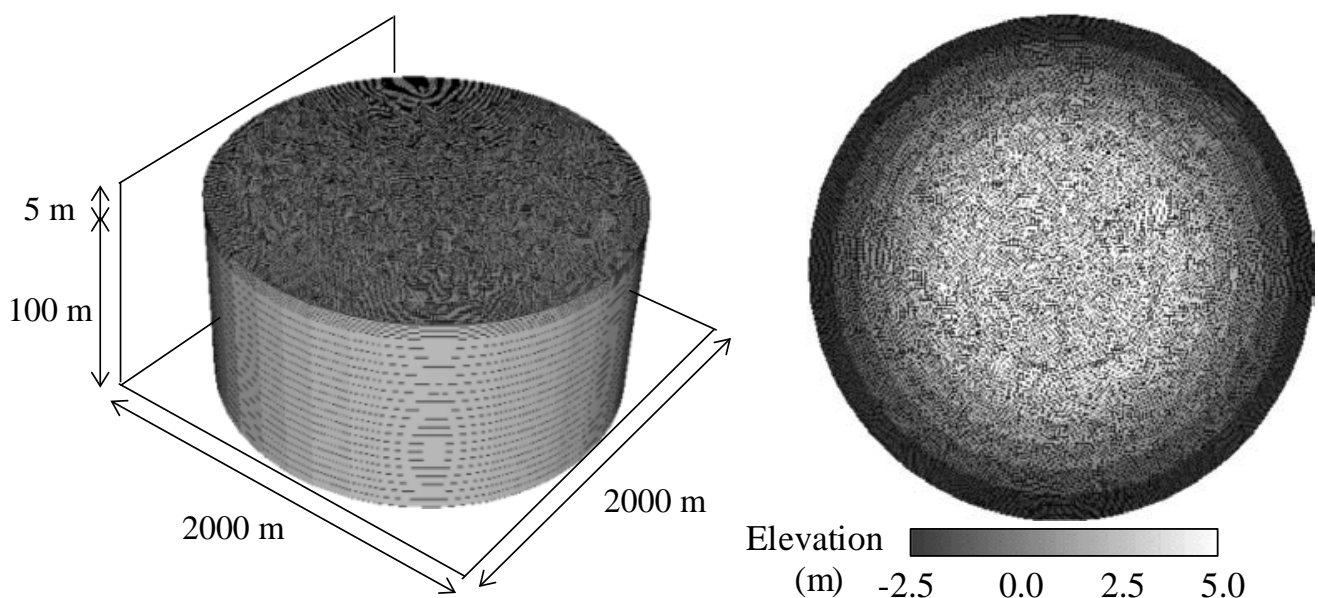

Figure 5. Oblique (left) and top (right) view of the 3-D finite-element mesh for the island model

Table 1. Input parameters used for SUTRA model simulations

\begin{tabular}{ll}
\hline Parameter & Value \\
\hline Hydraulic conductivity $\left(\mathrm{m} \mathrm{day}^{-1}\right)$ & 85 \\
\hline Longitudinal and transverse dispersivity $(\mathrm{m})$ & $10,0.1$ \\
\hline Porosity $(-)$ & 0.3 \\
\hline Freshwater and seawater concentration $\left(\mathrm{kg} \mathrm{kg}^{-1}\right)$ & $0,0.0357$ \\
\hline Freshwater and seawater density $\left(\mathrm{kg} \mathrm{m}^{-3}\right)$ & 1000,1025 \\
\hline Coefficient of fluid density change with concentration $\left(\mathrm{kg} \mathrm{m}^{-3} \mathrm{~kg}^{-1}\right)$ & 700 \\
\hline Fluid dynamic viscosity $\left(\mathrm{kg} \mathrm{m}^{-1} \mathrm{~s}^{-1}\right)$ & 0.001 \\
\hline Molecular diffusion $\left(\mathrm{m}^{2} \mathrm{~s}^{-1}\right)$ & $10^{-9}$ \\
\hline Fluid and matrix compressibility $\left(\mathrm{m} \mathrm{s}^{2} \mathrm{~kg}^{-1}\right)$ & $4.47 \times 10^{-10}, 10^{-8}$ \\
\hline Land surface slope $\left(\mathrm{m} \mathrm{m}^{-1}\right)$ & 0.0125 \\
\hline
\end{tabular}


Three scenarios of (i) existing condition (pre-SLR), (ii) SLR of $0.5 \mathrm{~m}$ and (iii) SLR of $1.0 \mathrm{~m}$ are considered. The simulations are run for 20 years with a time step of 0.2 year until the system reaches equilibrium. The applied spatial and temporal discretization satisfies the Peclet $(\mathrm{Pe})$ and Courant $(\mathrm{Cr})$ number criterion for numerical stability of the SUTRA code. Figure 6 shows the steady-state salinity and velocity distributions before SLR (existing condition), with freshwater in blue and seawater in red. A mixing zone is seen between the freshwater and seawater region. The sharp freshwater-seawater interface from the analytical solution (solid line) is compared with the freshwater-seawater transition zone predicted by the numerical model. The simulated lens thickness is $18.3 \mathrm{~m}$, which is in a reasonable agreement with the analytical result of $17.4 \mathrm{~m}$ ( $5 \%$ difference). The separation between freshwater outflow in the upper layer and seawater inflow in the lower layer is clearly visible. Changes in current direction in the mixing region along the sharp interface indicate that the water from both regions is drawn into the mixing region and transported towards the sea. This movement causes an increase in the shearing velocity at the interface. Figure 7 shows the simulated freshwater lenses for SLR of $0.5 \mathrm{~m}$ and $1.0 \mathrm{~m}$, illustrating areal loss of freshwater lens due to seawater inundation when compared to the pre-SLR condition. The simulated lens thickness and their corresponding volume are given in Table 2. For this hypothetical island, some changes of the freshwater lens thickness due to SLR are observed. The maximum freshwater lens thickness is reduced by $2.7 \%$ and $8.2 \%$ corresponding to SLR of 0.5 and $1.0 \mathrm{~m}$. For SLR of $1.0 \mathrm{~m}$, the freshwater-seawater interface moves landward by $80 \mathrm{~m}$, indicating increased salinization of aquifer with $\sim 20 \%$ inundation of land area and $\sim 25.6 \%$ loss in freshwater volume (see Figure 8).
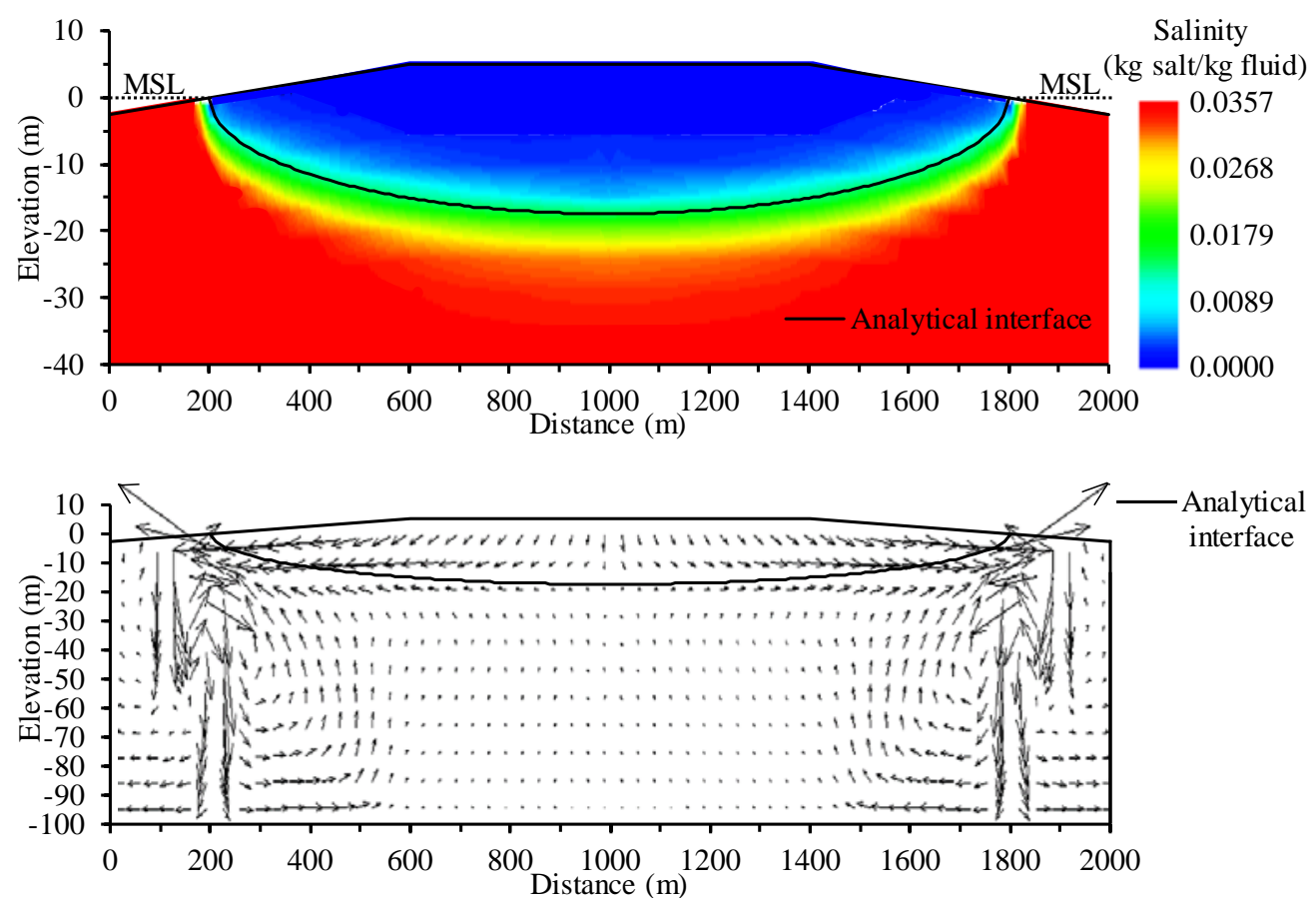

Figure 6. Steady-state salinity (top) and velocity (bottom) distributions before SLR
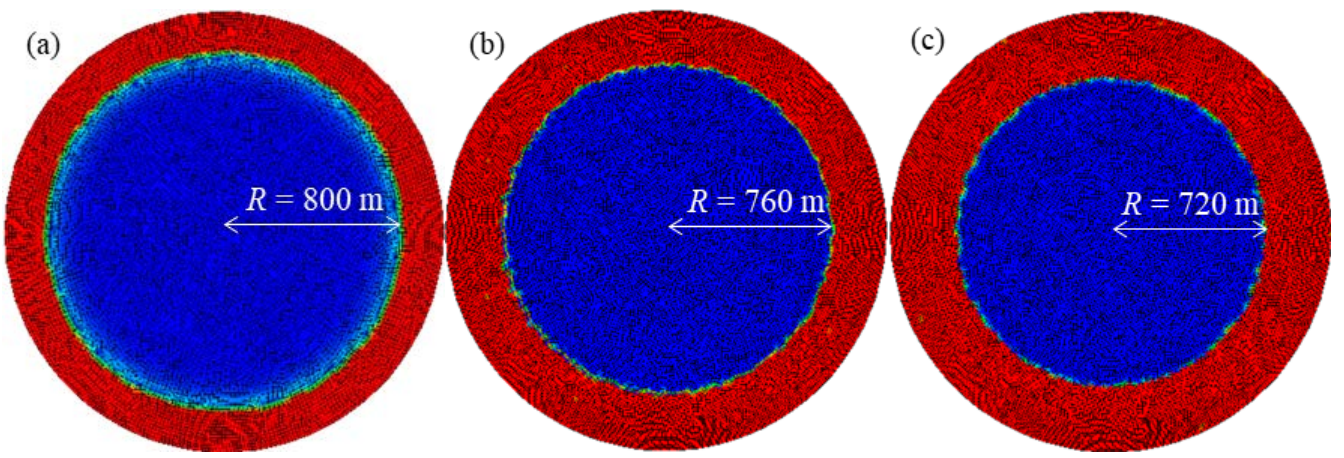

Figure 7. The change in the radius of the freshwater lens in response to sea level rise: (a) existing condition (pre-SLR), (b) SLR of $0.5 \mathrm{~m}$ and (c) SLR of $1.0 \mathrm{~m}$ 
Table 2. Groundwater availability and freshwater requirement for RWH for the two SLR scenarios

\begin{tabular}{ccccc}
\hline SLR (m) & Lens thickness $(\mathrm{m})$ & Lens volume $\left(\mathrm{m}^{3}\right)$ & $\begin{array}{c}\text { Recharge rate required to maintain } \\
\text { lens volume }\left(\mathrm{m} \mathrm{yr}^{-1}\right)\end{array}$ & $\begin{array}{c}\text { Freshwater } \\
\text { requirement for RWH } \\
(\%)\end{array}$ \\
\hline 0.0 & 18.30 & $7,543,816.32$ & 0.75 & - \\
\hline 0.5 & 17.80 & $6,622,275.26$ & 1.13 & 34 \\
\hline 1.0 & 16.80 & $5,609,631.28$ & 1.56 & 72 \\
\hline
\end{tabular}

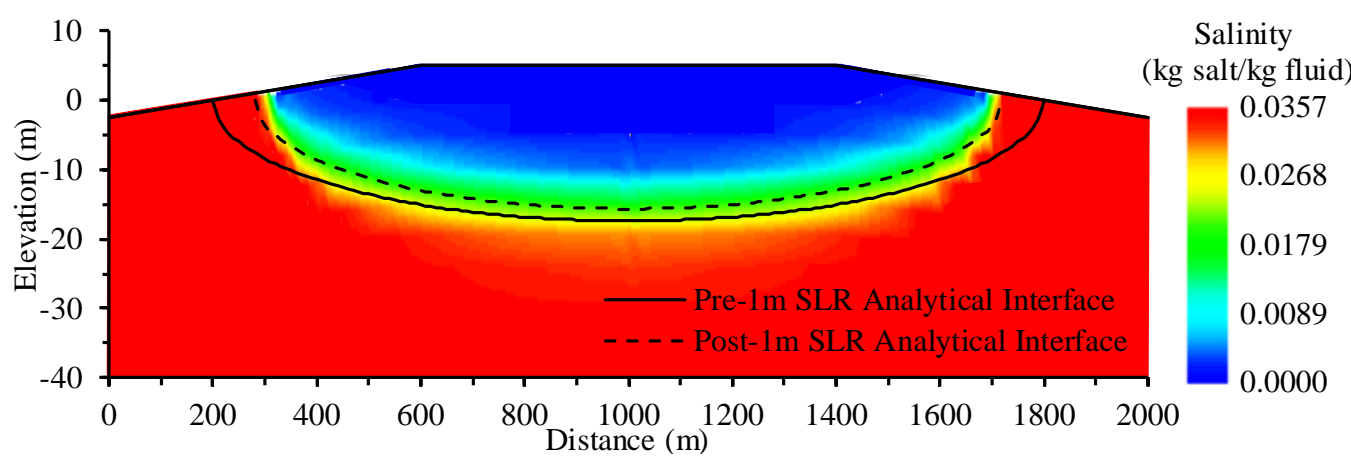

Figure 8. Steady-state salinity distribution in response to SLR of $1.0 \mathrm{~m}$

\section{Rainwater Harvesting}

Sea level rise could reduce the availability of freshwater supply for coastal communities by infiltrating groundwater and rendering it saline and undrinkable without any further treatment. This will pose a significant risk in achieving SDG 6 that aims to ensure universal access to clean water and sanitation. Rainwater harvesting (RWH), by collecting rainwater runoff from roofs or ground surfaces, receives increasing attention as an alternative water supply source for long-term water sustainability. The collected water can be stored in tanks for later domestic use or directed to recharge groundwater aquifer. In this section, we provide an estimation of RWH capacity needed to mitigate the loss of groundwater aquifer due to SLR for the hypothetical island case presented in the earlier section. The water harvesting potential $V\left(\mathrm{~m}^{3} \mathrm{yr}^{-1}\right)$ can be calculated via Equation (11).

$$
V=C \times P \times A \times E
$$

Here, $C(-)$ is the runoff coefficient, $P\left(\mathrm{~m} \mathrm{yr}^{-1}\right)$ is the annual rainfall, $A\left(\mathrm{~m}^{2}\right)$ is the catchment area and $E(-)$ is the collection efficiency accounting losses due to evaporation and catchment retention [19]. Based on the simulation results presented in Section 4, for a SLR scenario of $0.5 \mathrm{~m}$, only $90 \%$ of the pre-SLR land area is available to receive recharge from rainfall. To keep the lens volume at pre-SLR level, a recharge rate of $1.13 \mathrm{~m}$ $\mathrm{yr}^{-1}$ is needed to maintain the lens volume. With the existing recharge rate of $0.75 \mathrm{~m} \mathrm{yr}^{-1}$ from precipitation, an additional rate of $1.13-0.75=0.38 \mathrm{~m} \mathrm{yr}^{-1}$ is required to recharge the groundwater aquifer. Assuming that $60 \%$ of the total rainfall is lost by runoff [20] and collection efficiency is $100 \%$, the amount of rainwater that can be effectively harvested can be calculated as follows:

$$
\begin{aligned}
& \text { Island catchment area }=\pi \times 760 \mathrm{~m}^{2} \\
& \qquad=1814584 \mathrm{~m}^{2}
\end{aligned}
$$

Additonal recharge requirement

$$
\begin{aligned}
& =0.38 \mathrm{~m} \mathrm{yr}^{-1} \text { ? } 814584 \mathrm{~m}^{2} \\
& =689542 \mathrm{~m}^{3} \mathrm{yr}^{-1}
\end{aligned}
$$

Percentage of required RWH

$$
\begin{aligned}
& =689542 / 2041407 \times 100 \% \\
& \approx 34 \%
\end{aligned}
$$

Hence, for this island, 34\% of rainwater runoff should be collected to counteract the loss of groundwater due to salinity intrusion under a SLR scenario of $0.5 \mathrm{~m}$. Based on an average annual rainfall of $1.875 \mathrm{~m}, 689,542 \mathrm{~m}^{3}$ of water can potentially be collected from a total catchment area of $689,542 / 1.875=367,756 \mathrm{~m}^{2}$, which is equivalent to approximately 2450 houses with an average roof surface area of $150 \mathrm{~m}^{2}$. For each house, a roof catchment area of $150 \mathrm{~m}^{2}$ that receives annual rainfall of $1.875 \mathrm{~m}$ will be able to capture $1.875 \times 150=281.25 \mathrm{~m}^{3}$ of rainwater per year. The roof-collected rainwater is then diverted into a storage tank for later use. It is generally estimated that the storage tank size should be around 5\% of the annual rainwater supply [21]. The required storage tank size can be calculated as follows: 


$$
\begin{aligned}
& \text { Total annual rainfall }=1.875 \mathrm{~m} \mathrm{yr}^{-1} \\
& \begin{aligned}
\text { Roof catchment area }=150 \mathrm{~m}^{2} \\
\text { Storage requirement }=1.875 \mathrm{~m} \mathrm{yr}^{-1} \times 150 \mathrm{~m}^{2} \times 0.05 \\
=14.06 \mathrm{~m}^{3}
\end{aligned} \\
& \text { Height of tank }=2 \mathrm{~m} \\
& \text { Radius of tank }=\sqrt{14.06 \mathrm{~m}^{3} /(\pi \times 2 \mathrm{~m})}=1.5 \mathrm{~m} \\
& \text { Size of tank }=\pi \times 1.5 \mathrm{~m} \times 1.5 \mathrm{~m} \times 2 \mathrm{~m}=14.14 \mathrm{~m}^{3}
\end{aligned}
$$

Therefore, a cylindrical tank with radius $1.5 \mathrm{~m}$ and height $2 \mathrm{~m}$ is needed for the required water storage capacity of $14.06 \mathrm{~m}^{3}$. For SLR scenario of $1 \mathrm{~m}$, a higher additional recharge rate of $1.56-0.75=0.81 \mathrm{~m} \mathrm{yr}^{-1}$ is required to recharge the groundwater aquifer. As a result, the island is greatly in need of an effective RWH system in order to collect $72 \%$ of rainwater runoff, which would require a cylindrical storage tank with radius $1.8 \mathrm{~m}$ and height $3 \mathrm{~m}$.

\section{Conclusions}

In this paper, a three-dimensional groundwater flow and solute transport model SUTRA is used to simulate the dynamics of freshwater lens in response to SLR. Good agreement is found between the analytical and numerical solutions for lens thickness. Sensitivity analysis indicated that, among recharge rate, island radius and aquifer hydraulic conductivity, the freshwater lens thickness is most significantly affected by island radius. Numerical simulations are then carried out to quantify the impact of these geo-hydrologic parameters on fresh groundwater sustainability. The thinning of freshwater lens is observed to be linearly correlated with decreasing recharge rate and decreasing width of the island. Further, the lens thickness decreases logarithmically with increasing aquifer hydraulic conductivity. An increase in sea level could reduce the island's width, thereby reducing the available volume of extractable water within the freshwater lens. Our analysis suggests that for a SLR of $0.5 \mathrm{~m}, 34 \%$ of rainwater runoff needs to be collected and directed to recharge the groundwater aquifer in order to maintain the groundwater aquifer at pre-SLR level. This level of rainwater harvesting can be achieved by having a cylindrical tank of radius $1.5 \mathrm{~m}$ and height $2 \mathrm{~m}$ built for each of 2450 houses on the island. For a SLR of $1 \mathrm{~m}$, it is estimated that about $72 \%$ of rainwater runoff should be harvested to counteract the loss of groundwater. The scale of rainwater harvesting facility for this scenario would double those for the $0.5 \mathrm{~m} \mathrm{SLR}$. This study has provided a quantitative assessment of using RWH to mitigate the effect of SLR on coastal aquifer essential for sustainable management and development of water resources towards achieving SDG 6.

\section{Acknowledgements}

Financial support provided by Kementerian Pendidikan Malaysia FRGS Grant 203/PMATHS/6711569 and L'Oreal-UNESCO Women in Science Fellowship 2017 is gratefully acknowledged.

\section{REFERENCES}

[1] UN-Water. Nature-based Solutions for Water, United Nations World Water Development Report, UNESCO, 2018.

[2] W. P. Jr. Anderson. Aquifer Salinization from Storm Overwash, Journal of Coastal Research, Vol.18, No.3, 413420, 2002.

[3] T. F. M. Chui, J. P. Terry. Influence of Sea-level Rise on Freshwater Lenses of Different Atoll Island Sizes and Lens Resilience to Storm-induced Salinization, Journal of Hydrology, Vol.502, 18-26, 2013.

[4] O. Kalaoun, M. Jazar, A. Al Bitar. Assessing the Contribution of Demographic Growth, Climate Change, and the Refugee Crisis on Seawater Intrusion in the Tripoli Aquifer, Water, Vol.10, No.8, 973, 2018.

[5] B. Ataie-Ashtiani, S. D. Werner, C. T. Simmons, L. K. Morgan, C. Lu. How Important is the Impact of Land-surface Inundation on Seawater Intrusion Caused by Sea-level Rise? Hydrogeology Journal, Vol.21, No.7, 1673-1677, 2013.

[6] P. Rasmussen, T. O. Sonnenborg, G. Goncear, K. Hinsby. Assessing Impacts of Climate Change, Sea Level Rise and Drainage Canals on Saltwater Intrusion to Coastal Aquifer, Hydrology and Earth System Sciences, Vol.17, No.1, 421443, 2013.

[7] H. Sulzbacher, H. Wiederhold, B. Siemon, M. Grinat, J. Igel, T. Burschil, T. Gunther, K. Hinsby. Numerical Modelling of Climate Change Impacts on Freshwater Lenses on the North Sea Island of Borkum Using Hydrological and Geophysical Methods, Hydrology and Earth System Sciences, Vol.16, 3621-3643, 2012.

[8] V. Post, M. Eichholz, R. Brentführer. Groundwater Management in Coastal Zones, German Federal Institute for Geosciences and Natural Resources, Hanover, 2018.

[9] M. Saleem, A. Hussain, G. Mahmood. A Systematic Approach for Design of Rainwater Harvesting System and Groundwater Aquifer Modeling, Applied Water Science, Vol.8, No.5, 137, 2018.

[10] C. I. Voss, A. M. Provost. A Model for Saturated-unsaturated, Variable-density Ground-water Flow with Solute or Energy Transport, Water-resources Investigation Report 02-4231, U.S. Geological Survey, 2003.

[11] P. A. Hsieh, R. B. Winston. User's Guide to Model Viewer, a Program for Three-dimensional Visualization of Ground-water Model Results, Open File Report 02-106, U.S. Geological Survey, 2002. 
[12] S. Y. Teh, H. L. Koh, D. L. DeAngelis, M. Turtora. Interaction between Salinity Intrusion and Vegetation Succession: a Modeling Approach, Theoretical and Applied Mechanics Letters, Vol.3, No.3, 032001, 2013.

[13] J. Dupuit. Études Théoriques et Pratiques sur le Mouvement des Eaux dans les Canaux Découverts et à Travers les Terrains Perméables [Theoretical and Practical Studies of Water Movement in Open Channels and Permeable Rocks], Dunod, Paris, 1863.

[14] V. Arnold. A Note on the Ghyben-Herzberg Formula, Hydrological Sciences Journal, Vol.13, No.4, 43-46, 1968.

[15] D. E. Gualbert. Density Dependent Groundwater Flow: Salt Water Intrusion, Interfaculty Centre of Hydrology Utrecht, Utrecht, 2001.

[16] N. Chitnis, J. M. Hyman, J. M. Cushing. Determining Important Parameters in the Spread of Malaria through the Sensitivity Analysis of a Mathematical Model, Bulletin of Mathematical Biology, Vol.70, No.5, 1272-1296, 2008.

[17] C. Lu, P. Xin, J. Kong, L. Li, J. Luo. Analytical Solutions of Seawater Intrusion in Sloping Confined and Unconfined Coastal Aquifers, Water Resources Research, Vol.52, No.9, 6989-7004, 2016.

[18] IPCC. Climate Change 2013: the Physical Science Basis, Working Group 1 Contribution to the Fifth Assessment Report of the International Panel On Climate Change, Cambridge University Press, 2013.

[19] X. V. Alegre, N. Tynan. Preliminary Project Plan for a Rainwater Harvesting System for the Complexe De L'Etoile Du Sahel (Tunisia), Preliminary Report, Municipality of Sousse, 2014.

[20] A. J. Rachwal, D. Holt. Urban Rainwater Harvesting and Water Reuse: Review of Potential Benefits and Current UK Practices, Technical Report FR/G0006, Foundation for Water Research, 2008.

[21] M. Sarada. Roof-top Harvesting of Rainwater: an Answer to Present Day Water Crisis of India (with Special Reference to West Bengal), Journal of Environmental Science, Toxicology and Food Technology, Vol.9, No.6, 36-42, 2015. 